\title{
The Relationship Between Attitudes Toward Technology, Adaptability, And Customer Orientation Among Professional Salespeople
}

Bruce D. Keillor, (Email: keillor@uakron.edu), University of Akron Charles E. Pettijohn, Southwest Missouri State University Michael d'Amico, University of Akron

\begin{abstract}
The use of computer technology is increasingly becoming a way of life for professional salespeople. Given the increased use of technology in virtually aspects of sales, it would seem natural to reconcile both the uses of, and attitudes toward, computers among professional salespeople with traditionally emphasized sales constructs such as adaptability and customer orientation. The results of such an analysis would have implications for both academic sales research as well as sales managers and trainers who would benefit from an investigation into a propensity to accept computer technology and the ability to engage in significant sales activities that represent the human dimension. The current study addresses this issue by assessing the relationships between salespersons' attitudes toward computer technology, adaptability, and customer orientation. The findings generally indicate a positive predisposition toward computer usage and a significant positive relationship between those attitudes and both adaptability and customer orientation among a sample of professional salespeople.
\end{abstract}

Introduction

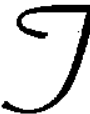
he use of computer technology is increasingly becoming a way of life for professional salespeople. Whether it is in the form of computer-based contact management, electronically generated activity reports, portable multimedia presentations, or any one of a number of other sales-focused applications, salespeople are being called on to integrate technology into virtually all of their activities. Among its many advantages, technology can help facilitate buyer-seller interactions, build stronger relationships by providing a forum for better identifying buyer needs, and allows for quick and easy customization of information targeted at individual customers (cf. Keillor, Bashaw and Pettijohn 1997).

The collision between technology and sales is unavoidable. However, before technology changes are to be quickly and successfully implemented in the sales process, the relationship between technology, its perceived role in selling activities, and traditionally important individual salesperson's characteristics need

Readers with comments or questions are encouraged to contact the authors via email. 
to be considered. Traditionally, certain individual characteristics have been considered desirable for salespeople to possess. In particular, abilities related to improving the quality of the buyer-seller interaction have received high levels of attention since the sales literature began to thoroughly explore issues related to relationship-building in sales (c.f. Dwyer, Schurr, and Oh 1987). It has generally been accepted that individuals who demonstrate an ability to adapt to a variety of selling situations and the specific needs of a given buyer will be better able to form strong buyer-seller relationships as well as being more productive.

Given the increased use of technology in virtually all aspects of sales, it would seem natural to reconcile both the uses of, and attitudes toward, computers among professional salespeople with these traditionally desired traits of adaptability and customer orientation. For example, do individuals who demonstrate the ability to adapt to a variety of buyer-seller environments also demonstrate that same type of flexibility in incorporating tools, such as technology, into these interactions, or is adaptability limited to interpersonal skills? Similarly, do individuals with a propensity to orient their selling activities toward the customer recognize the value of computer technology in sales or does a gap exist? Exploring these issues should provide valuable practical insights for sales managers in such areas as productivity improvement and training as well as bringing previous, established, theoretical sales constructs into an up-to-date context. To that end, the purpose of this study is to explore the relationship between adaptability, customer orientation, and salespersons' attitude toward the use of computer technology in their sales activities.

\section{Customer Orientation and Adaptability in Sales}

The customer orientation and adaptability of individual salespeople, and the importance of these characteristics for effective long-term performance, has been a focus of a substantial amount of research in the sales literature. In terms of a customer orientation, support for the practice of customer oriented selling has existed for a number of years. Saxe and Weitz (1982) set the stage for fully developing this line of inquiry through the introduction of the first generally accepted scale (Selling Orientation-Customer Orientation, or SOCO, scale) designed to assess the customer-orientation of sales representatives.

Early research showed, at best, mixed results when personal characteristics were used to predict salesperson performance (Churchill et al. 1985). However, a subsequent study (Kelley 1992) examined the concept of one particular personal characteristic, customer orientation, and found it to be an important characteristic of high performers. High performers are generally described as being committed to meeting customer needs and were perceived as being "advocates" of their clients' needs. The existing sales literature generally agrees that customer orientated selling leads to increased profits and customer satisfaction, and that the SOCO scale is one means of effectively measuring a salesperson's customer orientation. At the same time, there is little existing research which addresses how the nature and relevance of this customer orientation may be impacted in the dynamic selling environment of the future, particularly given the increased use of technology in buyer/seller interactions. Clearly, success in the sales environment of the future requires a customer orientation. The question to be addressed is how does a customer orientation, based on its interpersonal contact focus, relate to an individual's attitude toward technology--an ever increasing means through which buyers and sellers interact.

Similar to a customer orientation, sales advocates have also long supported the notion of adaptability in sales as another personal characteristic capable of positively impacting performance. It is frequently argued that personal selling is the only promotional vehicle which allows its messages to be adapted and adjusted to meet the needs of the receiver/buyer. Communication style is commonly associated with adaptive selling, or a salesperson's ability to adjust their activities to better match the interactive requirements of the buyer. Williams and Spiro (1985) examined the communication styles of sales representatives and customers and 
determined that the most successful salespersons will be ones who can adapt their communication styles appropriately to interact with the customer.

Spiro and Weitz (1990) directly address the relationship between adaptive selling and sales effectiveness through their development of a scale (ADAPTS) which measures a salesperson's adaptive behavior and interpersonal flexibility. The original scale consists of 16 items and has been shown to have a reliability, as measured by Cronbach's Alpha of approximately .85 (Cronbach 1951). The results of Spiro and Weitz's (1990) work show that the ADAPTS scale was positively related to self-reported measures of salesperson performance. Spiro and Weitz (1990) suggest that the ADAPTS scale could be used in sales environments appropriate for adaptive selling to indicate whether poor sales performance is the result of a lack of flexibility in the salesperson's's approach. Levy and Sharma (1994) also tested the ADAPTS scale and concluded that the ADAPTS scale could be used as a sales management tool to diagnose potential problems related to adaptability and better focus training efforts designed to improve adaptability.

All of this previous research suggests that, as computer technology becomes more pervasive in sales and a more integral part of the buyer-seller interaction, the relationship between traditionally conceived perspectives on adaptability and computer technology needs to be explored. In particular, any positive relationship between adaptability in a buyer-seller context and using computers in sales activities may indicate that adaptability is a characteristic which extends beyond interpersonal interaction. This, in turn, might suggest that bighly adaptable individuals may be more receptive to training, especially technology training, resulting in the gaining and maintaining of higher levels of productivity among this group (Keillor, Bashaw, and Pettijohn 1997).

When attitudes of salespeople toward the integration of computer technology into the sales realm is evaluated, many potential responses may be anticipated. On an intuitive level, it may seem natural to anticipate that sales personnel might offer significant degrees of resistance to computer technology. Possible explanations underlying such resistance could originate from several different sources (cf. Keillor, Bashaw, and Pettijohn 1997).

First, resistance could stem from a salesperson's innate fear of technology. This fear may have its genesis in the perception that using computer technology is beyond the individual's skills or capabilities. A second factor which may inhibit the adoption of computer technology is based on the notion that salespeople may fear the loss of freedom which could accompany the use of technology. In such an instance, the salesperson may feel that technology enables management to more closely monitor and direct their activities. A third factor limiting a positive predisposition toward technology could be the result of perceptual fears the salesperson might experience regarding the demand for their services. In other words, this perception may result from the salesperson's fear that technology will reduce, or eliminate, their job. Finally salespeople may resist the use of computer technology based on their perception that the new technology might interfere with their flexibility and/or creativity in performing sales activities. This perception may arise from the belief that the technology will actually "make the salesperson work harder" because of the increased reporting and analyzing responsibilities that may accompany incorporating computer technology into sales and selling activities.

In this study, two of these fears could be relevant in terms of their impact on the practice of customer oriented selling and adaptive selling. First, the fear of technology may be related. Secondly, the perception that computer technology might result in more work for the salesperson may also lower levels of customerorientation and adaptive selling as an individual characteristic. This perception would indicate the salesperson recognizes that customer-oriented and adaptive sales activities require time and effort. If 
additional time and effort is devoted to tasks involving the use of computer technology the result would be a lower level of customer oriented and adaptive selling activities. Saxe and Weitz (1982) state that salespeople with "the time to investigate and satisfy customer needs, and the support of their company, have higher SOCO scores." It is possible the computer may provide the organizational support and time required to investigate and satisfy customer needs and would, therefore, be associated with higher levels of customer orientation.

In a similar vein, Spiro and Weitz (1990) contend the practice of adaptive selling is enhanced when: 1) "a knowledge structure that facilitates recognition of different sale situations and access to sales strategies appropriate for each situation" exists, and 2) "the collection of information about the sales situation that facilitates adaptation" is available. The use of computer technology can increase the possibilities that these two situations exist and thus could increase the practice of adaptive selling. Previous research suggesțs that the relationship between the constructs used here is uncertain. It is the position of this research that a positive predisposition toward the use of computer technology will be associated with higher levels of both customer orientation and adaptability. This position is predicated on the notion that sales representatives who are using computer technology have developed positive attitudes toward its use through the realization that the technology has significantly enhanced their productive time and, not coincidentally, also increased their ability to engage in both customer-oriented and adaptive selling activities.

\section{Methodology}

The sample for this study was generated from members of a national professional sales association. A mail survey was sent to the 366 members of the professional sales organization located in the selected region. 126 responses obtained resulted in an effective response rate of 34.4 percent was consistent with prior studies of this type. A review of the sample characteristics showed that the respondents were full-time professional salespeople compensated on a straight commission basis with an average of eight years experience within the industry. A gender breakdown showed 56 percent of the sample were male and 44 percent were female. It could be argued that the competitive pressures placed on salespeople operating under a straight commission compensation plan are greater than those faced by individuals compensated purely on a salary basis, or some combination of the two. However, it should be noted that the two constructs being investigated in this study (i.e., adaptability and customer orientation) are treated in the sales literature as being directly related to selling activities and the sales process. This being the case, it was determined that individuals who are compensated on a straight commission basis would be more likely than other groups of salespeople to be focused directly on selling as their means on compensation is tied to the sales process and its outcome.

The respondents were asked to answer a variety of questions including those relevant to their adaptability (ADAPTS), selling orientation/customer orientation (SOCO), and attitude toward computer technology as a part of their sales job. The respondents were asked to indicate the extent to which they agreed or disagreed with each item based on a Likert-type scale ranging from $1=$ strongly disagree to $7=$ strongly agree. As discussed above, adaptability and selling orientation/customer orientation were measured using the established ADAPTS (Spiro and Weitz 1990) and SOCO (Saxe and Weitz 1982) scales. The respondents' attitudes toward computer technology as a part of their sales job was measured using Rajaeli's (1986) nine-item scale. The reliabilities obtained for each scale was $.83, .81$, and .84 respectively and exceeded the minimum coefficient alpha of .70 recommended by Nunally (1978). 


\section{Analysis}

Prior to any comparisons being made between the ADAPTS and SOCO constructs and the respondent salesperson's attitude toward computers, a profile of the role of computers in the respondent's sales activities provides valuable information. This profile is based on the type of computer technology used, the importance of computer technology for performing sales tasks, the extent to which the respondent's current technology meets their needs in the context of their sales activities, and the activities which the respondent sales people perform using computer technology. From the perspective of type of technology employed by the respondents, 51.7 percent reported primarily using some form of office, or shared, computer while 48.3 percent primarily used their own personal computer. The most common operating environment utilized by the sample was Windows-based $(60.2 \%)$, followed by DOS-based architecture (33.7\%) and Apple Macintosh systems $(6.0 \%)$.

In terms of the extent to which the respondents rated the value of computer technology to them in performing their sales responsibilities, 73.4 percent reported a computer to be either important or very important to them in their job. Approximately 44 percent of the respondents agreed or strongly agreed that their current technology met the needs of their sales activities. The most common use of technology (38.4\%) was providing buyers with product data, followed by completing paperwork $(24.7 \%$ ), and managing buyer data $(15.1 \%)$. Less than 10 percent indicated the primary use of computer technology to be managing time or managing product information. Further, the respondents were basically in agreement with the items dealing with computers having a positive impact on individual competitiveness, productivity, job satisfaction, and the use of computers in a sales job. At the same time, the respondents basically disagreed with the notions that computers represented a threat to job security, that computers were a threat to employee privacy, and the computers should not be used as an active part of the selling process or to interact with customers.

The initial analysis involved the development of a regression model to investigate both the linear and curvilinear nature of the relationships between overall attitude toward technology, adaptability, and selling orientation/customer orientation. This analysis was conducted based on the possibility that, while technology may save time and enhance a customer orientation and adaptability, too much may be negatively related. For example, too much emphasis on technology by a salesperson may serve to alienate he or she from a potential customer. The regression model used was:

$\mathrm{Y}=\mathrm{b}_{0}+\mathrm{b}_{1} \mathrm{X}_{1}+\mathrm{b}_{2} \mathrm{X}_{1}{ }^{2}+\mathrm{b}_{3} \mathrm{X}_{2}+\mathrm{b}_{4} \mathrm{X}_{2}{ }^{2}+\mathrm{e}$

where,

$\mathrm{Y}=$ Attitude toward technology

$\mathrm{X}_{1}=\mathrm{SOCO}$

$\mathrm{X}_{2}=$ ADAPTS

Using the technique suggested by Pedhazur (1982), step-wise regression was employed to test for the possibility that a curvilinear relationship exists between attitude toward technology and the independent variables SOCO and ADAPTS. The overall model was significant $(\mathrm{p}<.01)$ with an adjusted R-square of .249. The results were consistent with a linear relationship. Both the $S O C O(t=2.561 ; \mathrm{p}=.012)$ and ADAPTS $(\mathrm{t}=3.337 ; \mathrm{p}=.001)$ were significant while neither transformed variable $\operatorname{SOCO}^{2}(\mathrm{t}=1.275 ; \mathrm{p}$ $=.205)$ or $\operatorname{ADAPTS}^{2}(\mathrm{t}=.437 ; \mathrm{p}=.663)$ were found to be significant. 
The discussion now turns to the relationship between adaptability, selling orientation/customer orientation, and specific attitudes toward the use of computer technology among individual salespeople. In order to accomplish this, the procedure employed involved establishing norms for adaptability (ADAPTS) and selling orientation/customer orientation (SOCO) using the guidelines established by Churchill (1979). Individuals falling into the "high" and "low" categories, or norms, for each of these two constructs, based on Churchill's (1979) recommendations, were compared across the nine-item computer attitude scale using paired t-tests. While the partialing of the respondent's results in some data loss, the purpose of establishing the two categories was to clearly identify those individuals exhibiting strong/weak customer orientation and adaptability tendencies:

The scoring of the ADAPTS and SOCO scales follows the established guidelines. In the case of ADAPTS, the 16 items are summed and then divided by 16 for an individual's mean adaptability score (Spiro and Weitz 1990). The scoring of the SOCO scale is performed by summing the 22 items (Saxe and Weitz 1982; Michaels and Day 1985). The ADAPTS mean score and standard deviation for this sample were 4.986 and .796 respectively which are comparable to the results obtained by Spiro and Weitz (1990) in their original scale development research. Similarly, the SOCO mean score of 147 with a standard deviation of 9 was also comparable to other previous research (Saxe and Weitz 1982; Michaels and Day 1985). Thus, a low adaptability score for this sample was determined to be less than, or equal to, 3.4 while a high score was greater than, or equal to, 6.6. Using the same logic, a low SOCO score was established as less than, or equal to, 126 and a high SOCO score greater than, or equal to, 162 . Of the 126 respondents 30 fell into the "low" ADAPTS category, 25 in the "high" ADAPTS category, 24 into the "low" SOCO category, and 38 into the "high" SOCO category. These classifications were then subjected to paired t-tests across the nine items of the attitude toward computers scale (Rajaeli 1986).

The first series of comparisons involved adaptability and attitudes toward using computers in a sales job. Of the nine comparisons, four were statistically significant. Table 1 shows the results of this part of the data analysis.

\begin{tabular}{|c|c|c|}
\hline \multicolumn{3}{|c|}{ TABLE 1} \\
\hline \multicolumn{3}{|c|}{ Adaptability and Attitude Toward Computers } \\
\hline Item & $\begin{array}{l}\text { Low } \\
\text { Adaptability }\end{array}$ & $\begin{array}{l}\text { High } \\
\text { Adaptability }\end{array}$ \\
\hline I would like to see part or all of my job done by a computer. & 4.20 & 4.84 \\
\hline Computerizing part of my job would make me more competitive. & 4.93 & 5.56 \\
\hline Using a computer has significantly increased my sales productivity. & 4.40 & $5.36 * *$ \\
\hline $\begin{array}{l}\text { Using a computer has significantly increased my satisfaction with my } \\
\text { job. }\end{array}$ & 4.60 & 5.28 \\
\hline I like the idea of learning new ways to use a computer. & 5.30 & 5.76 \\
\hline $\begin{array}{l}\text { I would discourage anyone from allowing a computer to become an } \\
\text { active part of the selling process. }\end{array}$ & 2.82 & 2.44 \\
\hline $\begin{array}{l}\text { I am concerned that I might lose my job because of the increasing } \\
\text { emphasis on computer technology in sales. }\end{array}$ & $2.60^{*}$ & 1.40 \\
\hline $\begin{array}{l}\text { I think the introduction of computer technology will result in a loss } \\
\text { of employees' privacy. }\end{array}$ & $2.63^{* *}$ & 1.72 \\
\hline $\begin{array}{l}\text { I would not feel comfortable using a computer to interact with } \\
\text { customers. }\end{array}$ & $3.43^{*}$ & 1.52 \\
\hline
\end{tabular}

$*$ Sig. p <.01; ** Sig. $\mathrm{p}<.05$ 
The results of the adaptability comparisons identified some noteworthy significant differences. The highly adaptive group reported significantly higher levels of agreement with the notion that using a computer has significantly increased their sales productivity. At the same time, this group reported significantly lower levels of concern that computer technology might threaten their job security and employee privacy. This group also reported they would generally feel confortable using a computer to interact with customers. These results might suggest that, in addition to being highly adaptive in terms of buyer-seller interactions, these individual's adaptability may also extend to fundamental changes in the selling process (e.g., using a computer to interact with customers).

From the perspective of the high and low categories based on selling orientation/customer orientation, some similar results were obtained (see Table 2):

\begin{tabular}{|l|l|l|}
\hline \multicolumn{3}{|c|}{ TABLE 2 } \\
\hline \multicolumn{2}{|c|}{ Selling Orientation/Customer Orientation (SOCO) and Attitude Toward Computers } \\
\hline \multicolumn{1}{|c|}{ Item } & $\begin{array}{l}\text { Low } \\
\text { SOCO }\end{array}$ & $\begin{array}{l}\text { High } \\
\text { SOCO }\end{array}$ \\
\hline I would like to see part or all of my job done by a computer. & 4.75 & 5.18 \\
\hline Computerizing part of my job would make me more competitive. & 4.95 & $\mathbf{5 . 8 1 * *}$ \\
\hline Using a computer has significantly increased my sales productivity. & 4.62 & 5.07 \\
\hline Using a computer has significantly increased my satisfaction with my job. & 4.75 & 5.42 \\
\hline I like the idea of learning new ways to use a computer. & 5.20 & 5.78 \\
\hline $\begin{array}{l}\text { I would discourage anyone from allowing a computer to become an active part } \\
\text { of the selling process. }\end{array}$ & 2.69 & 2.23 \\
\hline $\begin{array}{l}\text { I am concerned that I might lose my job because of the increasing emphasis } \\
\text { on computer technology in sales. }\end{array}$ & $\mathbf{2 . 4 1 * *}$ & 1.65 \\
\hline $\begin{array}{l}\text { I think the introduction of computer technology will result in a loss of } \\
\text { employees' privacy. }\end{array}$ & 2.45 & 2.05 \\
\hline I would not feel comfortable using a computer to interact with customers. & $\mathbf{2 . 8 3 *}$ & 1.81 \\
\hline
\end{tabular}

* Sig. p < .01;** Sig. $\mathrm{p}<.05$

Just as was the case with highly adaptive sellers, those in the highly customer oriented group reported significantly low levels of concern that computer technology threatened their job security as well as no reluctance in using computers to interact with customers. This same group also reported significantly higher levels of agreement with the statement that computerizing at least a portion of their job would increase their competitiveness.

\section{Discussion and Implications}

In today's selling environment, salespeople must continually cope with change. Changes come in numerous varieties: economic, competition, customers, product, and technology. In general, a sales representative must either adapt or eventually begin disengaging (cf. Ornstein, Cron, and Slocum 1989). Thus, the notion that one's ability to adapt to buyers and the ability to adapt to other changes such as technological changes seems logical. Since adapting to any changes generally requires significant efforts, one could argue that a willingness/ability to adapt to new technology should relate directly to the willingness/ability to adapt to individual customers. The findings of this analysis discovered that 
salespeople who possessed more positive attitudes toward new technology also possessed a greater proclivity in adapting to their customers. Thus, the selection of sellers who are more open minded and more willing to recognize options that can help facilitate the "work smarter" rather than only "working harder" (Sujan, Weitz, and Sujan 1988) may indeed be positive for the firm. These results indicate that firms operating in dynamic environments may be well advised to select salespeople who are neither afraid of change nor hesitant to adapt their selling tactics to unique situations. Further, training salespeople may be affected by the fact that working with salespeople to alleviate the fear of implementing new technology may have ramifications in the development of training programs designed to engender more positive attitudes toward adaptive selling.

In a different vein, one can argue that when a salesperson engages in either customer oriented or adaptive selling activities that this engagenent comes at a significant cost to the salesperson. This cost may be incurred whether through the physical and mental efforts that are required or through a more direct cost of time. As a salesperson engages in customer-oriented and adaptive selling activities, that person is required to focus greater attention on the customer. Such attention requires that the salesperson recognizes that the customer's requirements supersede the salesperson's requirements and, consequently, the salesperson's immediate needs may go unsatisfied in an effort to build the sales relationship. Further, salespeople who engage in adaptive selling and/or customer-oriented selling recognize that time is required. To many salespeople, their sales time is exceptionally valuable, therefore the decision to engage in either adaptive or customer-oriented selling is one that must be reconciled in some fashion.

Perhaps such a reconciliation may be facilitated by the fact that salespeople more attuned to computer technology recognize that the use of computer technology provides them with resources which may be used in the adaptive and customer-oriented selling efforts. For example, high adaptability salespeople scored significantly higher on the dimension related to the perception that the computer increased their productivity. This may be indicative of a perception that since the computer has increased productivity that they now have resources available to engage in more adaptive selling activities. Similarly, the perception of high customer-oriented salespeople that computer usage makes them more competitive may indicate that they are now capable of focusing on providing "customer delight." The issue related to the use of the computer to interact with customers also may be perceived as being indicative of a resource which may be used to reduce the amount of time the salesperson is required to devote to the role, which provides more time to engage in such relationship activities as being customer-oriented and adaptive in the sales encounter.

The use of computer technology also provides resources in addition to time. The technology may provide the technologically proficient salesperson with another valuable resource: information. Information garnered through computer usage may facilitate both adaptive and customer-oriented selling by providing the salesperson with a greater knowledge of customer needs and requirements which may facilitate both adaptive selling and customer-oriented selling. For example, if a salesperson learns of a special challenge or requirement of a particular customer, that salesperson is in a better position to begin adapting the solution package offered and the presentation of that package to coincide with both the customer's needs and information requirements. Further, by engaging in such activities, the salesperson is also engaging in customer oriented selling as an attempt is made to custonize the solution to meet the customer's situation. Additionally, such information may also allow the customer to develop better solutions.

Many factors probably interact to explain the relationship between a salesperson's positive attitude toward technology usage and that individual's interest in, and ability to, engage in adaptive and customeroriented selling. One can argue that adaptability is a global trait that is present for an individual in numerous situations, whether related to personal interaction or changing environments. Thus, one's 
propensity to adapt to new computer technology may be highly correlated with the propensity to adapt to unique customer situations. The ability to adjust to change in one situation may presage the ability to adjust to a second situation. For the sales manager, this may help explain why his or her best salespeople may be the very ones more willing to recognize and seek opportunities to improve. As Miller and Heimann (1985) point out, the best salespeople are those who continually seek to improve and are not satisfied with the status quo. This position would mean that the sales manager has a significant responsibility in terms of challenging the sales force to continually strive to develop, learn and grow as individuals, and grow as salespeople. Perhaps this could be accomplished through either additional training or by providing low risk challenging opportunities which promote both experimentation and development.

In conclusion, a second factor may also be responsible for the results which generally showed a relationship between positive attitudes toward computer usage and tendencies to engage in customeroriented and adaptive selling. This factor may essentially be identified as resource availability. Quite simply, it seems that managers continually demand more from their sales force. Managers not only desire increased in sales volume and profitability, they also want salespeople to complete more extraneous assignments such as research, service, installation, delivery, collections, etc. The demands on a salesperson's time may preclude the individual from gaining greater knowledge of either the customer or the product/service being sold. The combination of limited time and limited knowledge may result in limited use of either adaptive or customer-oriented selling. However, salespeople who have successfully integrated the use of computer technology into their sales roles may have also discovered that this tool provides them with more customer and "product" knowledge, as well as greater work efficiency, resulting in more time available for their sales activities. Thus, the combination increases the salesperson's resources in terms of knowledge and time provides the salesperson with the means to engage in adaptive selling activities.

\section{Limitations}

In conclusion, several limitations of the study should be noted. These fall into one of two basic categories: sample-related and measurement-related. In the case of the former, the type of respondent raises some potential problem issues. First, the reliance on commission salespeople could create potential problems for generalizing the findings. As discussed earlier, commission salespeople were used primarily due to the competitive nature of their jobs. Assuming that technology is viewed as a means for being more productive, or increasing competitive competencies, such salespeople would be a good choice. Alternatively, it may be that the time needed to effectively employ technology may not be viewed as a good investment among salaried salespeople. Another issue, related to the respondents, is the constructs included in the study. Other potential influencing variables related to attitudes toward technology might include respondent age, education level, and current performance level which could have a significant impact. Finally, one important measurement-related issue is the SOCO and ADAPTS scales themselves. These scales were designed to measure phenomena that are fundamentally buyer-seller in nature. In this study we made the connection between what are essentially personal interaction attitudes and attitudes toward something (i.e. technology) which is job-related but not of a personal nature.

The authors would like to acknowledge the valuable contribution of Marketing Editor Kathy Pettit-O'Malley and two anonymous reviewers in the preparation of this manuscript. 


\section{References}

1. Churchill, Gilbert A. (1979), "A Paradigm for Developing Better Measures of Marketing Constructs," Journal of Marketing Research, Vol. 16, February, pp. 64-73.

2. Churchill, Gilbert A., Neil Ford, Steven W. Hartley, and Orville C. Walker, Ir. (1985), "The Determinants of Salesperson Performance: A Meta-Analysis," Journal of Marketing Research, Vol. 22, pp. 103-118.

3. Cronbach, Lee J. (1951), "Coefficient Alpha and the Internal Structure of Tests," $p_{\text {sychometrika, Vol. }}$ 16, September, pp. 297-334.

4. Dwyer, Robert F., Paul H. Schurr, and Sejo Oh (1987), "Developing Buyer-Seller Relationships," Journal of Marketing, Vol. 51, April, pp. 11-27.

5. Keillor, Bruce D., R. Edward Bashaw, and Charles E. Pettijohn (1997), "Sales Force Automation Issues Prior to Implementation: The Relationship Between Attitudes Toward Technology, Experience, and Productivity," Journal of Business and Industrial Marketing, Vol. 12, pp. 209-219.

6. Kelley, Scott W. (1992), "Developing Customer Orientation Among Service Employees," Journal of the Academy of Marketing Sciences, Vol. 20, pp. 27-36.

7. Levy, Michael and Arun Sharma (1994), "Adaptive Selling: The Role of Gender, Age, Sales Experience, and Education," Journal of Business Research, Vol, 31, pp. 39-47.

8. Michaels, Ronald and Ralph L. Day (1985), "Measuring Customer Orientation of Salespeople: A Replication with Industrial Buyers," Journal of Marketing Research, Vol. 22, November, pp. 443-446.

9. Miller, Robert B. and Stephen E. Heiman (1985), Strategic Selling, New York: Warner Books.

10. Nunally, J.C. (1978), Psychometric Theory, $2^{\text {nd }}$ Edition, New York: McGraw-Hill.

11. Ornstein, Suzyn, William L. Cron, and John W. Slocum (1989), "Life Stage versus Career Stage: A Comparative Test of the Theories of Levison and Super," Joumal of Organizational Behavior, Vol. 10, April, pp. 117-134.

12. Pedhazur, Elazar, J. (1982), Multiple Regression in Behavioral Research, $2^{\text {nd }}$ Edition, New York: Holt, Rinehart, and Winston Inc.

13. Rajaeli, Anat (1986), "Employee Attitude Toward Working with Computers," Joumal of Occupational Behaviour, Vol. 7, pp. 89-106.

14. Rummel, R.J. (1967), "Unđerstanding Factor Analysis," Journal of Conflict Resolution, Vol. 1, December, pp. 444-480.

15. Saxe, Robert and Barton A. Weitz (1982), "The SOCO Scale: A Measure of the Customer Orientation of Salespeople," Journal of Marketing Research, Vol. 19, August, pp. 343-351.

16. Spiro, Rosann and Barton A. Weitz (1990), "Adaptive Selling: Conceptualization, Measurement, and Nomological Validity," Journal of Marketing Research, Vol. 27, February, pp. 61-69.

17. Sujan, Harish, Barton A. Weitz, and Mita Sujan (1988), "Increasing Sales Productivity by getting Salespeople to Work Smarter," Journal of Personal Selling and Sales Management, Vol. 8, August, pp. 9-19.

18. Williams, Kaylene C. and Rosann L. Spiro (1985), "Communication Type in the SalespersonConsumer Dyad," Journal of Marketing Research, Vol. 22, November, pp. 434-442. 